cookery, at the present day, does not consist in learning how to compound and cook food so that it may be the most easily digested, and the best fitted to sustain the functions of life, but rather that it may be the most tempting to the appetite. I would by no means recommend so great a simplicity of diet as has been urged by some of our wise modern philosophers. I would not confine the human race to the use of mashed potatoes, stewed apples and bran bread, even with the addition of a little butter. No, we should not think this the natural diet of man. In fact, this kind of diet is the farthest possible from natural diet, the whole posse of the moral reformers and would-be philosophers to the contrary notwithstanding. Human nature needs something more substantial than this. Let it have, for instance, a plenty of bread and beef; and a little wine, if properly taken, can do it no manner of harm. Give it good, wholesome, nutritious food, but let that food be properly cooked. We would not take it raw from the hand of nature, without any cookery to fit it for use ; this would be as much as to say that we are unable to prepare the rough product and fit it for our wants. Neither would we have it spoiled by the art of cookery; this would be showing that we think too much of what we shall eat and what we shall drink. But we would have it prepared in such a manner that it retain all its natural nutritious qualities, and at the same time be palatable and wholesome. We cannot imagine that man can be reformed solely by attention to dietetic rules, as some have imagined; yet we are fully convinced, that if men would return more nearly to their pristine state of living, as regards their food, it would have a tendency to make them longer lived, and to elevate them in the scale of moral and intellectual beings.

The foregoing are some of the most prominent circumstances which have tended to render the moderns inferior to the ancients as regards their morals, their intellect, their corporeal powers, and the length of their lives. To pursue the subject farther, and to enter more minutely into particulars, would not only, perhaps, require a more profound knowledge of history and a deeper philosophy than we possess, but would, probably, be both wearying and unprofitable to the reader. Begging pardon, therefore, for having already so long trespassed upon the pages of the Journal, we will draw our remarks to a close.

Buxton, Me., August, 1840.

\title{
HERMAPHRODITISM.
}

[Communicated for the Boston Medical and Surgical Journal.]

TrE following curious case of imposture came under my observation in the month of March, 1840. was represented as being an hermaphrodite. I was requested to examine him, the superintendent being at a loss whether to place him in the male or female department of the institution. His external appearance was as follows. Hair, black and long, arranged after the feminine mode. 
Face, having a masculine coarseness, but with a fair, feminine complexion. Some beard on the chin and upper lip, which bad evidently never been shaven. Ear-rings in the ears. Hands, delicate but large. Feet, large and masculine. He was dressed in pantaloons and a frock coat. His voice and manner of walking resembled those of a female. The former in tone was not peculiarly feminine, but the air and manner of speaking strikingly so. The gait, in walking, was so peculiar, that no one could avoid the suspicion that the individual was a woman in male attire. I was informed that he had been carried before a magistrate, on the charge of being a female disguised in men's clothing, and by him sent, in the first place, to the jail, and from thence to the Almshouse. He had previously been known about some portions of the city as an hermaphrodite; and I was told that stories were current of his performing the copulative functions of either sex.

When requested to exhibit the sexual organs, he seemed to manifest much bashfulness, and said that he was reluctant to do so then, as he was menstruating. Entreaty, bribery and threats were successively employed, but without effect in procuring a voluntary examination. The superintendent not feeling authorized to compel an exhibition, he was, with his consent, examined by an old woman, an inmate of the house. She reported that he was endowed with perfectly formed male and female organs. This not being satisfactory, and stimulating curiosity, frequent attempts, at subsequent periods, were made to procure an examination, but unsuccessfully. In the meantime, the old woman who had enjoyed the privilege of inspection having stated it to be her opinion that the female organs predominated, he was established in one of the female wards. He replied to all questions readily; said he had no inclination for either sex; and represented himself, in short, as a female, with, to use his own language, "a piece of dead flesh hanging down." He stated that he had been brought up as a girl, had lived in service as a kitchen maid in this city; and, formelly, had performed as a female in a circus. At the Almshouse he was employed in female duties, such as washing, \&c., with which he was evidently perfectly au fait. After a few weeks he was seized with pneumonia, which terminated fatally.

Having much curiosity to make the examination after death, which had been sought unsuccessfully during life, I proceeded, accompanied by a medical friend, to the Almshouse for this purpose, inmediately upon receiving intelligence of his demise. The result may be described in a few words. We found male organs entire and well developed, and no semblance whatever of those of the female. Dr. N., who accompanied me, recognized him as an individual who had applied to him for a certificate that he possessed male organs. His object in soliciting the certificate, he stated, was to avoid prosecution for being a female disguised in male attire. His case, previously to his being brought before a magistrate, had excited much interest among some benevolent ladies. He had stated to them that he had of late dressed like a male, to avoid the importunities of the sex! His story was credited, and much sympathy and pecuniary aid were bestowed upon him. The imposture must, manifestly, have been commenced at an early age. The motives 
which led to its adoption by himself or others, and induced its continuance, I leave for conjecture. His age was apparently about 25.
Buffalo, N. Y., Sept., 1840.
A. F.

BOSTON MEDICAL AND SURGICAL JOURNAL.

BOSTON, OCTOBER 7, 1840 .

\section{LECTURES ON THE THEORY AND PRACTICE OF PHYSIC.}

IT was remarked by a medical gentleman, the other day, that there were so many systems of practice extant, that he had no confidence in any of them. A sentiment like this could only have emanated from a superficial student, who never felt the responsibilities of professional life to be very troublesome. The only mode of keeping pace with the advances of the age, is to study all publications which have their origin in a respectable source; and in the practice of medicine, especially, a neglect to profit by the accumulating experience of others, shows an unfitness in the man for the station which sociely permits him to occupy.

Dr. Stokes's reputation stands very high in Europe; but that circumstance has no very direct influence on the minds of American physicians, since they have sagacity to discover merit, and the wisdom to avail themselves of the attaininents of others, without regard to country. Messrs. Haswell, Barrington \& Haswell, of Philadelphia, have recently published a second edition of Dr. Stokes's Lectures, enriched and very essentially enhanced in value by the addition of twelve lectures, together with numerous notes, by John Bell, M.D., of that city. The whole now makes a large volume of almost 700 pages, octavo. Considerable, if not all of the original work, has been read in the journals; but Dr. Bell's contributions are quite new, and therefore cannot fail of exciting considerable interest. We enjoin it upon the students of medical schools to be provided with this book at once, as a necessary appendage in attending lectures on theory and practice.

Preservation of the Teeth.-Books are written upon all supposable subjects in these times of literary energy, and what surprises us most, is the fact that so many of them are instructive. A neatly-printed miniature volume on the preservation of the teeth, by David K. Hitchcock, has been already alluded to in the Journal. At first view, it seemed hardly possible that the author of this little work could do anything more than reiterate the ten-times told stories of half a dozen authors. But the more closely this is read, the better it will be liked. The topics discussed are really worth attending to, and, to a certain extent, are individually important to every person.

There are 14 chapters. Chap. i. treats of the teeth as influencing the character of facial expression, health, \&c. Chap. iii. is devoted to the consideration of irregularity in dentition, with engraved illustrations. Chap. iv. considers the whole matter of filling teeth, and becomes right smart about the lithodeon, which is now considerably used in this place. Chap. v. plays off a whole park of artillery upon popular dentifrices. 